\title{
Effect of Dietary Rhodobacter capsulatus on Cholesterol Concentration and Fatty Acid Composition in Japanese Quail (Coturnix japonica) Egg
}

\author{
Ummay Salma ${ }^{1}$, Abdul G. Miah ${ }^{1}$, Takaaki Maki ${ }^{2}$ and Hirotada Tsujii ${ }^{1}$ \\ ${ }^{1}$ Laboratory of Animal Biotechnology, Interdisciplinary Graduate School of Science and Technology, \\ Shinshu University, Minamiminowa-Mura, Nagano 399-4598, Japan \\ ${ }^{2}$ Matsumoto Institute of Microorganisms Co., Ltd, Matsumoto, 390-1241, Japan.
}

\begin{abstract}
The aim of this study was to investigate the possible hypocholesterolemic effects of Rhodobacter capsulatus on cholesterol and triglycerides concentrations in serum, egg-yolk, and fatty acid composition in egg-yolk of quails. A total of 60, 10-week-old laying Japanese quails (Coturnix japonica) were randomly assigned into 3 treatment groups (20 quails/group), and fed diets supplemented with 0 (control), 0.02 , and $0.04 \%$ R. capsulatus for 6 weeks. Eggs and blood from each quail were collected at the end of the 6-week feeding period for chemical analysis. The cholesterol fractions in egg-yolk and serum were measured by enzymatic assay, and the fatty acid composition in egg-yolk was determined by gas chromatography. The results revealed that the supplementation of $0.04 \%$ dietary $R$. capsulatus reduced $(P<0.05)$ cholesterol and triglycerides concentrations in serum and in egg-yolk. High-density lipoprotein cholesterol was increased, and low-density lipoprotein cholesterol and the atherogenic index were decreased $(P<0.05)$ by dietary $R$. capsulatus. Hepatic cholesterol was also reduced $(P$ $<0.05)$ by $0.04 \% R$. capsulatus. Yolk color was improved $(P<0.05)$ by $0.04 \% R$. capsulatus supplemented diet. The concentrations of monounsaturated fatty acids and polyunsaturated fatty acids (PUFA) were increased ( $P$ $<0.05$ ) in egg-yolk of the quails fed the $0.04 \% R$. capsulatus supplemented diet than the control diet. The ratio of PUFA to saturated fatty acids in egg-yolk was improved $(P<0.05)$ by $0.04 \% R$. capsulatus supplemented diet. Therefore, the supplementation of dietary $R$. capsulatus may be a feasible means of producing quail eggs with lower cholesterol and higher PUFA content for health conscious consumers.
\end{abstract}

Key words: cholesterol, egg-yolk, fatty acid composition, Japanese quail, Rhodobacter capsulatus

J. Poult. Sci., 44: 375-382, 2007

\section{Introduction}

The quail egg is the animal product with the most equilibrating proteins, vitamin-minerals and enzymatic contents. It has also highly therapeutic powers. In some cases, it is more attractive to consumers than chicken egg due to its delicious taste, higher nutritional value, and spotted shell color. In spite of these facts, health conscious consumers have been avoiding it due to having higher concentration of cholesterol, 19.73-23.61 mg/g yolk (Mutia and Uchi- da, 1999).

The nutritive value of eggs depends unquestionably on the level of essential polyunsaturated fatty acids (PUFA), total cholesterol, low-density lipoprotein (LDL)-cholesterol and high-density lipoprotein (HDL)-cholesterol in the yolk. The positive association of elevated serum total cholesterol and LDL-cholesterol levels with atherosclerosis has been well established (Carlson et al., 1979). The cholesterol content and fatty acid composition of eggs have received increased attention due to the rela-

Received: March 23, 2007, Accepted: May 17, 2007

Correspondence: Prof. Hirotada Tsujii, Laboratory of Animal Biotechnology, Shinshu University, Minamiminowa-Mura, Nagano 399-4598, Japan. (E-mail: htsujii@gipmc-shinshu-u.ac.jp) 
tionship between dietary lipid and the incidence of atherosclerosis (Mutia and Uchida, 1999). Considerable efforts have been made to reduce the cholesterol content in eggs (Noble et al., 1990; Michella and Slaugh, 2000) with little success, and to manipulate fatty acid composition, with some success, in order to increase n-3 polyunsaturated fatty acids (Caston and Leeson, 1990; Leskanich and Noble, 1997).

The Rhodobacter capsulatus (ATCC 11166) is a photosynthetic bacteria reported as a highly beneficiary agent in the production of single-cell protein, water purification, and fish culture (Kobayashi and Kurata, 1978). Besides these, we observed that $R$. capsulatus causes a significant reduction in serum cholesterol and triglycerides concentrations in rats (Tsujii et al., 2007). Our other studies also demonstrated that $R$. capsulatus is a potent agent for lowering cholesterol concentrations not only in serum, but also in egg-yolk and the meat of chicken (Salma et al., 2007a, b). We also observed that dietary supplementation of $R$. capsulatus improved the ratio of unsaturated fatty acids (UFA) to saturated fatty acids (SFA) in the thigh and breast meat of broilers (Salma et al., 2007a). However, no information is available on the hypocholesterolemic effects of $R$. capsulatus on cholesterol fractions in quails. Therefore, the aim of this study was to investigate the possible hypocholesterolemic effects of $R$. capsulatus on the cholesterol and triglycerides concentrations in serum, egg-yolk and fatty acid composition in egg-yolk of Japanese quails.

\section{Materials and Methods}

\section{Birds, Management, and Diets}

A total of 70, 5-week-old female Japanese quails (Coturnix japonica) were collected from a local commercial flock. The conditions and standards of care employed in this study were in accordance with "Guideline for Regulation of Animal Experimentation, Faculty of Agriculture, Shinshu University". They were caged ( 2 birds per cage) with individual feed-trough and water-trough. Birds were fed a balanced commercial laying quail diet (Toyohashi Shiryo Co., Ltd., Aichi, Japan) as their daily requirement from 5 weeks prior to commencement of the study for adaptation, and to allow egg production to reach a standard level. The composition of the basal diet is shown in Table 1 . The $R$. capsulatus was grown in an outdoor culture under natural illumination as previously described (Kobayashi and Kurata, 1978). The cells of $R$. capsulatus were collected by centrifugation and spray-dried. The dried $R$. capsulatus powder was mixed with high soft mineral mix (MIM Co., Ltd., Matsumoto, Japan) as $1: 10$ and stored at $4{ }^{\circ} \mathrm{C}$. The dried $R$. capsulatus powder contained approximately $59.8 \%$ crude protein, $9.4 \%$ crude fat, $0.9 \%$ crude fiber and $9.4 \%$ ash determined by the AOAC (1985). The 60 laying quails, 10-week-old with almost the same body weight, were assigned into 3 dietary treatment groups under a completely randomized design, so that there were 20 quails in each group. The diets were supplemented with 3 levels of $R$. capsulatus: $0 \%$ as control group, and 0.02 and $0.04 \%$ as treatment groups. The diets were provided daily at $30 \mathrm{~g}$ per bird for a 6-week feeding period. Clean drinking

Table 1. Composition of basal $\operatorname{diet}^{1}$

\begin{tabular}{lr}
\hline \multicolumn{1}{c}{ Ingredient composition } & \multicolumn{1}{c}{$(\%)$} \\
\hline Ground corn and milo & 54.0 \\
Soybean meal and corn gluten meal & 27.0 \\
Wheat bran & 2.0 \\
Fish meal & 9.0 \\
Calcium carbonate, alfalfa meal, calcium & \\
$\quad$ phosphate, salt, paprika extract and palm oil & 8.0 \\
Calculated nutrient & \\
ME (Kcal/kg) & 2900 \\
Calcium & 2.5 \\
Available phosphorus & 0.6 \\
Lysine & 1.6 \\
Methionine & 0.9 \\
Carotenoids $(\mathrm{mg} / \mathrm{kg})$ & 8.9 \\
Analyzed nutrient & \\
Crude protein & 23.0 \\
Crude fat & 3.0 \\
Crude fiber & 6.0 \\
Crude ash & 14.0 \\
Total cholesterol $(\mu \mathrm{g} / \mathrm{g})$ & 80.0 \\
\hline
\end{tabular}

${ }^{1}$ Vitamin mix/mineral mix* was provided per kilogram of diet: Vitamin A, 5,000 IU; cholecalciferol, $2000 \mathrm{IU}$; Vitamin E, $11 \mathrm{IU}$; Vitamin $\mathrm{K}_{3}, 4.0 \mathrm{mg}$; Vitamin $\mathrm{B}_{1}, 1.5 \mathrm{mg}$; Vitamin $\mathrm{B}_{2}, 4.3 \mathrm{mg}$; nicotinic acid, $44 \mathrm{mg}$; Ca pantothenate, $12 \mathrm{mg}$; pyridoxin, $4.0 \mathrm{mg}$, choline $\mathrm{Cl}, 220 \mathrm{mg}$; folic acid, $0.5 \mathrm{~g}$; biotin, $220 \mu \mathrm{g}$; Vitamin $\mathrm{B}_{12}$, $10 \mu \mathrm{g}$.

* Mineral mix was replaced by high soft mineral mix (4 g per kilogram of diet), in which experimental Rhodobacter capsulatus were mixed. High soft mineral: $\mathrm{SiO}_{2}, 55.26 \% ; \mathrm{CaO}, 5.08 \%$; $\mathrm{MgO}, 1.53 \%$; Fe, 4.14\%; Al, 7.67\%; S, 1.74\%; Na, 0.84\%; C, $1.11 \% ; \mathrm{Cl}, 50(\mathrm{mg} / \mathrm{kg}) ; \mathrm{MnO}, 550(\mathrm{mg} / \mathrm{kg}) ; \mathrm{B}_{2} \mathrm{O}_{2}, 35(\mathrm{mg} / \mathrm{kg})$; $\mathrm{Cu}, 19$ (mg/kg); Zn, 80 (mg/kg); Co, 12 (mg/kg); Se, 1.6 (mg/ $\mathrm{kg}) ; \mathrm{Ni}, 19(\mathrm{mg} / \mathrm{kg}) ; \mathrm{V}, 14(\mathrm{mg} / \mathrm{kg}) ; \mathrm{Mo}, 3.6(\mathrm{mg} / \mathrm{kg}) ; \mathrm{I}, 10$ $(\mathrm{mg} / \mathrm{kg})$. 
water was supplied ad libitum. A lighting schedule began with 16 hours of light at 5 weeks of age with increases of 1 hour per week until 18 hours of light was reached at 9 weeks of age. This final lighting schedule was maintained throughout the study period.

\section{Record Keeping and Evaluation}

The quails were weighed individually on the first day and at the end of the 6-week feeding period and monitored daily for signs of morbidity and mortality. Daily feed intake was recorded, and feed conversion efficiency (feed intake:mass production) was calculated at the end of the 6 weeks of feeding. Daily egg production and individual egg weight were recorded to determine the egg mass production $(\mathrm{g} / \mathrm{d} / \mathrm{hen})$. Eggs from each quail were collected at the end of the 6-week feeding period for measurement of egg quality (egg weight, yolk weight, yolk index, yolk color, albumen height, Haugh unit and shell weight), as well as for analysis of cholesterol and triglycerides concentrations, and fatty acid composition in yolk. Yolk index was calculated as the ratio of yolk height to yolk width. Yolk color was evaluated using a Roche yolk color fan, and color was scored according to its intensity. Haugh unit was calculated using the Haugh unit formula (Haugh, 1937).

$$
\mathrm{HU}=100 \log \left(\mathrm{H}+7.57-1.7 \mathrm{~W}^{0.37}\right)
$$

Where, $\mathrm{HU}=$ Haugh unit; $\mathrm{H}=$ thick egg-white height $(\mathrm{mm}) ; \mathrm{W}=$ egg weight $(\mathrm{g})$.

Blood samples $(2.0 \mathrm{~m} l)$ from each individual quail were collected at the end of the 6-week feeding period. Blood was collected by neck dislocation after overnight feed deprivation. After standing at room temperature for 1 hour, serum was isolated by centrifugation at $1,000 \times \mathrm{g}$ for 10 minutes. Serum samples were stored at $-80^{\circ} \mathrm{C}$ until further analysis. Livers, were collected and washed with normal saline, blotted dry on filter paper, and weighed before freezing for storage.

\section{Yolk and Liver Sample Preparation}

One gram of each egg-yolk was homogenized with $15 \mathrm{ml}$ of chloroform-methanol 2:1 (by volume), sonicated, and filtered as previously described (Elkin and Rogler, 1990). From each liver samples, $1 \mathrm{~g}$ was homogenized with $12 \mathrm{ml}$ of chloroform-methanol 2:1 (by volume) and filtered directly into a $50 \mathrm{ml}$ volumetric flask using a glass micro fiber filter. Fol- lowing rehomogenization and refiltration, the liver filtrates were diluted to a final volume of $50 \mathrm{~m} l$ with chloroform-methanol 2:1 (by volume). In addition, to increase the concentration of lipid extract of the liver samples, the chloroform-methanol was removed by rotary evaporator (Virtis, Gardiner, NY, USA) following centrifugation $(1,000 \times \mathrm{g}$ for $10 \mathrm{~min})$ and filtration, and finally the dried extract was dissolved in $5 \mathrm{ml}$ of chloroform-methanol 2:1 (by volume). The lipid extract samples were stored at $-80^{\circ} \mathrm{C}$ until further analysis.

\section{Enzymatic Analysis}

Total cholesterol, triglycerides and HDL-cholesterol concentrations in the serum were determined enzymatically using commercially available reagent kits (Wako Tcho 439-17501, Wako TG 43240201 and Wako HDL-c 431-52501, respectively; Wako Pure Chemical Industries, Ltd., Tokyo, Japan). LDL-cholesterol was determined according to the formula of Friedwald et al. (1972):

$$
\begin{aligned}
& \text { LDL-cholesterol }=(\text { total cholesterol } \\
& \quad-\text { HDL-cholesterol })- \text { triglycerides } / 5 .
\end{aligned}
$$

The atherogenic index was calculated as the ratio of LDL-cholesterol to HDL-cholesterol. Total cholesterol and triglycerides concentrations in the eggyolk and liver were determined using the same reagent kits as those used for serum analysis.

\section{Fatty Acid Determination}

Total lipid extracts of yolk samples were transmethylated into fatty acid methyl esters and were separated by using a gas chromatograph (Simadzu, GC14B, Kyoto, Japan). Aliquots of $2 \mu \mathrm{l}$ were injected into an Omegawax 250 capillary column (30 $\mathrm{m} \times 0.25 \mathrm{~mm}$ i.d.; $0.25 \mu \mathrm{m}$ thickness; Supelco, Bellefonte, PA, USA) with cyanopropyl methyl silicone as stationary phase. Helium was used as the carrier gas at a constant flow rate of $4.7 \mathrm{ml} / \mathrm{min}$. The following oven temperature program was used: $100^{\circ} \mathrm{C}$ held for $1 \mathrm{~min}$, increased to $160^{\circ} \mathrm{C}$ at $40^{\circ} \mathrm{C} /$ min, then to $240^{\circ} \mathrm{C}$ at $7^{\circ} \mathrm{C} / \mathrm{min}$, and $240^{\circ} \mathrm{C}$ held for $10 \mathrm{~min}$. Peaks were separated using a flame-ionization detector and were quantified with an electric integrator (Shimadzu, CR-7A, Kyoto, Japan) using pure standard mixtures (Sigma, St. Louis, MO, USA), and were identified. We adopted the weight percentage of each fatty acid in all detected fatty acids as a measurement value. 


\section{Statistical Analysis}

Data were analyzed using Fisher's protected least significant difference test. The NCSS (Number Crunchier Statistical System, NCSS Statistical Software, Kaysville, UT, USA) Version 5.01 computer software package was used for all statistical analysis. All data are expressed as mean $\pm \mathrm{SE}$. Differences were considered significant at the level of $(P<0.05)$.

\section{Results}

The effects of dietary $R$. capsulatus on egg production, egg weight, egg mass, feed intake, feed conversion efficiency, and live weight changes in laying quails during the 6-week feeding period are shown in Table 2. The rate of egg production, egg weight, egg mass, feed intake, feed conversion efficiency and live weight changes did not differ significantly among the quails fed either $R$. capsulatus supplemented diets or the control diet.

The effects of dietary $R$. capsulatus on egg quality after the 6-week feeding period are shown in Table 3. Dietary supplementation of $0.04 \% R$. capsulatus in diet significantly $(P<0.05)$ increased the intensity of yolk color compared to the control diet. Yolk color was linearly increased in accordance with increasing levels of dietary $R$. capsulatus supplementation. Yolk weight, yolk index, albumen weight, Haugh unit and shell weight did not differ significantly among the quails, whether they were fed the control diet or a diet supplemented with $R$. capsulatus.

The influences of dietary $R$. capsulatus on total cholesterol and triglycerides concentrations in eggyolk, serum and liver of quails after the 6-week feeding period are shown in Table 4. Total cholesterol concentrations were 225.8, 171.2 and 165.2 $\mathrm{mg} / \mathrm{d} l$; and triglycerides concentrations were 106.3 , 101.8 and $92.6 \mathrm{mg} / \mathrm{d} l$ in serum of quails fed 0 (control), 0.02 and $0.04 \% R$. capsulatus supplemented diets, respectively. Total cholesterol and triglycerides concentrations in serum were significantly $(P<$ 0.05) reduced in the quails fed the $0.04 \% R$. capsulatus supplemented diet compared with those fed the control diet. HDL-cholesterol concentration

Table 2. Effect of dietary Rhodobacter capsulatus on production of laying Japanese quails during 6 weeks feeding period ${ }^{1}$

\begin{tabular}{lccc}
\hline \hline \multirow{2}{*}{\multicolumn{1}{c}{ Parameters }} & \multicolumn{3}{c}{ Level of dietary $R$. capsulatus $(\%)$} \\
\cline { 2 - 4 } & 0 (Control) & 0.02 & 0.04 \\
\hline Egg production (\%) & $74.7 \pm 6.6$ & $73.3 \pm 7.1$ & $71.1 \pm 6.4$ \\
Egg weight (g) & $10.2 \pm 0.2$ & $10.4 \pm 0.2$ & $10.8 \pm 0.1$ \\
Egg mass ${ }^{2}$ (g/d/bird) & $7.6 \pm 0.01$ & $7.6 \pm 0.02$ & $7.7 \pm 0.01$ \\
Feed intake (g/d/bird) & $29.6 \pm 2.4$ & $29.0 \pm 1.8$ & $28.5 \pm 1.78$ \\
Feed conversion efficiency & $3.9 \pm 0.38$ & $3.8 \pm 0.35$ & $3.7 \pm 0.29$ \\
Initial live weight (g/bird) & $132.7 \pm 4.4$ & $135.0 \pm 4.4$ & $139.0 \pm 4.3$ \\
Final live weight (g/bird) & $130.0 \pm 4.2$ & $137.5 \pm 3.2$ & $137.2 \pm 3.6$ \\
\hline
\end{tabular}

${ }^{1}$ All measurements were done as fresh basis; Values are mean $\pm \mathrm{SE}$ for 20 quails per group.

${ }^{2}$ Egg mass $=($ egg production $\times$ egg weight $) / 100$.

${ }^{3}$ Feed conversion efficiency $=$ feed intake: egg mass $(\mathrm{g}: \mathrm{g})$.

Table 3. Effect of dietary Rhodobacter capsulatus on egg quality of laying Japanese quails after 6 weeks feeding period ${ }^{1}$

\begin{tabular}{llcc}
\hline \hline \multirow{2}{*}{ Parameters } & \multicolumn{3}{c}{ Level of dietary $R$. capsulatus $(\%)$} \\
\cline { 2 - 4 } & $0($ Control $)$ & 0.02 & 0.04 \\
\hline Yolk weight $(\mathrm{g})$ & $3.20 \pm 0.05$ & $3.19 \pm 0.18$ & $3.16 \pm 0.04$ \\
Yolk index & $0.43 \pm 0.01$ & $0.45 \pm 0.01$ & $0.47 \pm 0.01$ \\
Yolk color & $11.3 \pm 0.3^{\mathrm{a}}$ & $11.50 \pm 0.22^{\mathrm{ab}}$ & $12.00 \pm 0.12^{\mathrm{b}}$ \\
Albumen weight $(\mathrm{g})$ & $6.04 \pm 0.20$ & $6.13 \pm 0.15$ & $6.19 \pm 0.08$ \\
Haugh unit & $91.5 \pm 0.6$ & $91.1 \pm 1.1$ & $92.4 \pm 1.2$ \\
Shell weight $(\mathrm{g})$ & $1.06 \pm 0.02$ & $1.10 \pm 0.04$ & $1.15 \pm 0.04$ \\
\hline
\end{tabular}

${ }^{\mathrm{a}, \mathrm{b}}$ Means within a row without common superscripts differ significantly $(P<0.05)$.

${ }^{1}$ All measurements were done as fresh basis; values are mean \pm SE for 20 quails per group. 


\begin{tabular}{|c|c|c|c|}
\hline \multirow{2}{*}{ Parameters } & \multicolumn{3}{|c|}{ Level of dietary $R$. capsulatus (\%) } \\
\hline & 0 (Control) & 0.02 & 0.04 \\
\hline \multicolumn{4}{|l|}{ Serum } \\
\hline Total cholesterol $(\mathrm{mg} / \mathrm{d} l)$ & $225.8 \pm 16.2^{\mathrm{a}}$ & $171.2 \pm 19.4^{\mathrm{ab}}$ & $165.2 \pm 24.1^{\mathrm{b}}$ \\
\hline Triglycerides $(\mathrm{mg} / \mathrm{d} l)$ & $106.3 \pm 5.3^{\mathrm{a}}$ & $101.8 \pm 2.1^{\mathrm{ab}}$ & $92.6 \pm 3.5^{\mathrm{b}}$ \\
\hline LDL-cholesterol $^{2}(\mathrm{mg} / \mathrm{d} l)$ & $179.3 \pm 12.7^{\mathrm{a}}$ & $121.0 \pm 16.7^{\mathrm{b}}$ & $114.1 \pm 22.3^{\mathrm{b}}$ \\
\hline HDL-cholesterol (mg/d $l$ ) & $25.2 \pm 2.4^{\mathrm{a}}$ & $29.81 \pm 2.3^{\mathrm{ab}}$ & $32.5 \pm 1.1^{\mathrm{b}}$ \\
\hline Atherogenic index ${ }^{3}$ & $7.1 \pm 1.0^{\mathrm{a}}$ & $4.1 \pm 0.7^{\mathrm{b}}$ & $3.5 \pm 0.3^{b}$ \\
\hline \multicolumn{4}{|l|}{ Egg-yolk } \\
\hline Total cholesterol $(\mathrm{mg} / \mathrm{g})$ & $14.2 \pm 0.9^{\mathrm{a}}$ & $13.0 \pm 0.6^{\mathrm{ab}}$ & $11.2 \pm 1.2^{\mathrm{b}}$ \\
\hline Triglycerides $(\mathrm{mg} / \mathrm{g})$ & $61.1 \pm 2.2^{\mathrm{a}}$ & $52.2 \pm 4.0^{\mathrm{ab}}$ & $47.8 \pm 3.6^{\mathrm{b}}$ \\
\hline \multicolumn{4}{|l|}{ Liver } \\
\hline Total cholesterol (mg/g) & $2.06 \pm 0.06^{\mathrm{a}}$ & $1.95 \pm 0.15^{\mathrm{ab}}$ & $1.66 \pm 0.11^{\mathrm{b}}$ \\
\hline Triglycerides $(\mathrm{mg} / \mathrm{g})$ & $11.8 \pm 1.32$ & $11.56 \pm 0.65$ & $10.6 \pm 0.96$ \\
\hline Weight (mg/100 g) & $3.10 \pm 0.17$ & $3.24 \pm 0.21$ & $3.11 \pm 0.27$ \\
\hline
\end{tabular}

was significantly $(P<0.05)$ increased and LDLcholesterol concentration was significantly $(P<$ 0.05 ) decreased in serum of the quails fed the $0.04 \%$ dietary $R$. capsulatus.

Total cholesterol concentrations were 14.2, 13.0 and $11.2 \mathrm{mg} / \mathrm{g}$ in egg-yolk of quails fed 0 (control), 0.02 and $0.04 \% R$. capsulatus supplemented diets, respectively. Egg-yolk cholesterol was significantly $(P<0.05)$ reduced in the quails fed $0.04 \% R$. capsulatus supplemented diet compared with those fed the control diet. Average triglycerides concentrations were $61.1,52.2$ and $47.8 \mathrm{mg} / \mathrm{g}$ in egg-yolk of the quails fed $0,0.02$ and $0.04 \% R$. capsulatus supplemented diets, respectively. Triglycerides concentration was also significantly $(P<0.05)$ lower in the egg-yolk of the quails fed the $0.04 \% R$. capsulatus supplemented diet than in the egg-yolk of the quails fed the control diet.

Although the hepatic cholesterol concentration was significantly $(P<0.05)$ reduced by the $0.04 \% R$. capsulatus supplemented diet, the hepatic triglycerides concentration was not significantly $(P<0.05)$ altered by dietary $R$. capsulatus. Liver weight also did not differ among the quails fed $R$. capsulatus supplemented diets.

The effects of dietary $R$. capsulatus on fatty acid composition (\% of total fatty acids) in egg-yolk of quails after the 6-week feeding period are shown in Table 5. The concentrations of UFA, oleic (18:1), linoleic (18:2), and linolenic (18:3) acids in egg-yolk were significantly $(P<0.05)$ increased by the $0.04 \%$ $R$. capsulatus supplemented diet as compared to the control diet. Among the SFA, palmitic acid (C16:0) was significantly $(P<0.05)$ decreased by the $R$. capsulatus $(0.04 \%)$ supplemented diet, whereas the concentration of stearic acid (C18:0) was not significantly altered by $R$. capsulatus supplemented diets. The concentrations of monounsaturated fatty acids (MUFA) and PUFA were significantly $(P<0.05)$ increased in egg-yolk of the quails fed the $0.04 \% R$. capsulatus supplemented diet as compared to that of the quails fed the control diet. The ratio of PUFA to SFA, or PUFA + MUFA to SFA, in egg-yolk was significantly $(P<0.05)$ improved by the $0.04 \% R$. capsulatus supplemented diet.

\section{Discussion}

This study evaluated the feasibility of sustainable improving the nutritional value of quail eggs by lowering cholesterol concentration and increasing PUFA content. It demonstrated that the cholesterol and triglycerides concentrations in serum of quails were reduced by dietary $R$. capsulatus. HDL-cholesterol concentration was increased, and LDL- 
Table 5. Effect of dietary Rhodobacter capsulatus on fatty acid composition ( $\%$ of total fatty acids) in egg-yolk of laying Japanese quails after 6 weeks feeding period ${ }^{1}$

\begin{tabular}{llcc}
\hline \multirow{2}{*}{ Fatty acids } & \multicolumn{3}{c}{ Level of dietary $R$. capsulatus $(\%)$} \\
\cline { 2 - 4 } & 0 (Control) & 0.02 & 0.04 \\
\hline $16: 0$ & $29.5 \pm 0.7^{\mathrm{a}}$ & $26.5 \pm 0.8^{\mathrm{ab}}$ & $24.4 \pm 1.8^{\mathrm{b}}$ \\
$18: 0$ & $12.4 \pm 1.0$ & $12.3 \pm 0.3$ & $10.9 \pm 1.2$ \\
$18: 1$ & $43.7 \pm 1.3^{\mathrm{a}}$ & $44.3 \pm 0.6^{\mathrm{ab}}$ & $46.5 \pm 1.1^{\mathrm{b}}$ \\
$18: 2$ & $11.9 \pm 0.7^{\mathrm{a}}$ & $13.1 \pm 0.6^{\mathrm{ab}}$ & $13.9 \pm 0.3^{\mathrm{b}}$ \\
$18: 3$ & $0.38 \pm 0.03^{\mathrm{a}}$ & $0.59 \pm 0.03^{\mathrm{ab}}$ & $0.67 \pm 0.14^{\mathrm{b}}$ \\
Others & $2.74 \pm 0.51$ & $2.70 \pm 0.15$ & $3.34 \pm 0.54$ \\
MUFA & $43.7 \pm 1.3^{\mathrm{a}}$ & $44.3 \pm 0.6^{\mathrm{ab}}$ & $46.5 \pm 1.1^{\mathrm{b}}$ \\
PUFA & $12.3 \pm 0.7^{\mathrm{a}}$ & $13.7 \pm 0.6^{\mathrm{ab}}$ & $14.6 \pm 0.4^{\mathrm{b}}$ \\
SFA & $41.9 \pm 0.9^{\mathrm{a}}$ & $39.2 \pm 1.0^{\mathrm{a}}$ & $35.4 \pm 2.6^{\mathrm{b}}$ \\
PUFA: SFA & $0.29 \pm 0.02^{\mathrm{a}}$ & $0.34 \pm 0.02^{\mathrm{ab}}$ & $0.41 \pm 0.02^{\mathrm{b}}$ \\
(PUFA + MUFA): SFA & $1.33 \pm 0.05^{\mathrm{a}}$ & $1.47 \pm 0.04^{\mathrm{a}}$ & $1.75 \pm 0.10^{\mathrm{b}}$ \\
\hline
\end{tabular}

${ }^{\mathrm{a}, \mathrm{b}}$ Means within a row without common superscripts differ significantly $(P<0.05)$.

${ }^{1}$ All measurements were done as fresh basis; values are mean $\pm \mathrm{SE}$ for 20 quails per group. MUFA $=$ monounsaturated fatty acids, PUFA $=$ polyunsaturated fatty acids, SFA $=$ saturated fatty acid.

cholesterol was reduced by the dietary $R$. capsulatus. As a result, the atherogenic index was lowered in the quails fed the $R$. capsulatus supplemented diet. These results are in agreement with our previous results observed in serum of rats (Tsujii et al., 2007), laying hens (Salma et al., 2007b) and broilers (Salma et al., 2007a) fed $R$. capsulatus supplemented diets.

Most of the cholesterol found in egg-yolk is synthesized in the liver, transported by the blood in the form of lipoproteins, and deposited in the growing follicles (Christie and Moore, 1972; Hillard et al., 1972; Hammad et al., 1996). Griffin (1992) reported that the correlation between yolk and serum fractions depends on the rate of endocytosis of LDL-cholesterol and the formation of the coated pit on the surface of growing follicles rather than on serum cholesterol concentration. In the present study, supplementation of $R$. capsulatus in the diet of laying quails also reduced egg-yolk cholesterol and hepatic cholesterol correlatively with serum cholesterol. These reductions of cholesterol fractions in egg-yolk are quite similar to the results obtained in laying hens (Salma et al., 2007b), and confirmed that dietary $R$. capsulatus was able to reduce not only serum cholesterol fractions but also egg-yolk cholesterol fractions.

However, the mechanism of hypocholesterolemic action of $R$. capsulatus is still unknown. $R$. capsulatus contain many known and unknown factors, which may regulate its hypocholesterolemic effects on serum and egg-yolk. Carotenoids are the most important cholesterol lowering agent present in the $R$. capsulatus with higher concentration (4.2\%; Kobayashi and Kurata, 1978). Carotenoid-rich diets are associated with reducing serum cholesterol concentration (Yeum and Russell, 2002). An explanation for the cholesterol lowering effect of $R$. capsulatus is the involvement of the specific combination and higher concentration of amino acids. $R$. capsulatus is an excellent source of arginine (3.34 $\%)$, glycine $(2.41 \%)$, and lysine $(2.86 \%)$, which have hypocholesterolemic effects (Vahouny et al., 1984). Lysine plays an important role in the production of carnitine that mediate the conversion of fatty acids into energy and helping to lower cholesterol (Finnin and Peters, 1996).

Another mechanism through which $R$. capsulatus may exert its hypocholesterolemic action is via bile acids. The reduction of cholesterol concentrations in serum and egg-yolk may be attributed to the reduced hepatic cholesterol content, which is due to the inhibition of the dietary cholesterol absorption as well as the excretion of the endogenous cholesterol by bile acids and inhibition of their reabsorption by dietary $R$. capsulatus. As a result, the created scarcity of the bile acids content in the blood stream may influence the liver to use cholesterol for synthesis of bile acids, and the synthesized bile acids are converted to bile salt to meet up the demands of 
lipid digestion and absorption (Chiu et al., 2006). Though in the present study, the amount of bile acid synthesis was not determined to support this speculation. Hepatic cholesterol reduction is highly correlated with the inhibition of cholesterol absorption and induced compensatory increases in both hepatic and intestinal $\beta$-hydroxyl $\beta$-methylglutaryl-Co-A (HMG-CoA) reductase activity, hepatic LDL-receptor level and hepatic internalization of circulating LDL-cholesterol (Harwood et al., 1993).

Yolk color has always been regarded as an important egg quality characteristic. In fact, consumers tend to associate golden yellow with orange yolk (Brufau, 1997). The color of egg-yolk is a dietary response, and a suitable degree of pigmentation. In this study, a higher concentration of carotenoids 4.2\% (Kobayashi and Kurata, 1978) in R. capsulatus responded similarly in improving egg-yolk color as well as chicken egg-yolk color (Salma et al., 2007b).

Observations made in the present study reveal that the dietary $R$. capsulatus could alter the composition of fatty acids in quail egg. We observed that the composition of fatty acids in broiler meat was altered by the supplementation of $R$. capsulatus in finisher diet (Salma et al., 2007a). Several nutritional studies strongly support a relationship between SFA and the risk of cardiovascular heart diseases, and hence there is a need to reduce the consumption of SFA and increase the consumption of PUFA. Linoleic acid and $\alpha$-linolenic acid are essential precursors of longer PUFA. However, their synthesis via elongation, desaturation, and $\beta$ oxidation is inefficient in human and thus they need to be delivered by the diet. This is due to synthesis of $\omega 6$ and $\omega 3$ PUFA from shorter precursors being catalyzed by the same enzyme complexes, including $\Delta 5$ - and $\Delta 6$-desaturases and elongases (Voss et al., 1991). Grundy (1989) showed that MUFA has a lowering effect on serum lipids in comparison to SFA. Phetteplace and Watkins (1990) reported that significant hypolipidemia was observed in chickens by increasing n-3 fatty acids and the PUFA:SFA ratio. In this study, the ratio between the diversified UFA and SFA was increased in egg-yolk by dietary $R$. capsulatus. Beynen and Katan (1985) indicated that polyunsaturated fatty acids promote oxidation, whereas saturated fatty acids, such as palmitic acid, promote lipid storage and liver lipoprotein synthesis.
Hypothetically, PUFA enhance hypolipidemia by decreasing the rate of cholesterol absorption and synthesis, transferring cholesterol from the bloodstream to tissues, changing the ratio of cholesterol to protein in LDL, changing the rates of synthesis or catabolism of individual lipoproteins, and increasing the excretion of neutral and acidic steroids (Goodnight et al., 1982).

Moreover, the dietary $R$. capsulatus did not appear to cause any illness or any adverse effects on production performances and egg quality compared with the same parameters for the quails fed the control diet. Therefore, it may be concluded that supplementation of $R$. capsulatus in the diet of laying quails offers a feasible way to produce eggs with lower cholesterol and higher PUFA content for health-conscious consumers.

\section{References}

Association of Official Analytical Chemists. Official Methods of Analysis 16th ed. AOAC. Arlington. 1985.

Beynen AC and Katan MB. Why do polyunsaturated fatty acids lower serum cholesterol. American Journal of Clinical Nutrition, 42: 560-563. 1985.

Brufau J. Yolk - The golden opportunity. International table egg production supplement. International Poultry Production, 5: 17-25. 1997.

Carlson LA, Böttiger LEB and Åhfeldt. Risk factors for myocardial infarction in the Stockholm prospective study. Acta Medica Scandinavica, 206: 351-360. 1979.

Caston L and Lesson S. Dietary flax and egg composition. Poultry Science, 69: 1617-1620. 1990.

Chiu HC, Lu TY, Tseng YY and Pan TM. The effects of Lactobacillus-fermented milk on lipid metabolism in hamsters fed on high-cholesterol diet. Applied Microbiology and Biotechnology, 71: 238-245. 2006.

Christie WW and Moore JH. The lipid components of the plasma, liver and ovarian follicles in the domestic chicken (Gallus gallus). Comparative Biochemistry and Physiology (B), 41: 287-295. 1972.

Elkin RG and Rogler JC. Reduction of the cholesterol content of eggs by the oral administration of lovastatin to laying hens. Journal of Agricultural and Food Chemistry, 38: 1635-1641. 1990.

Finnin B and Peters S. Amino acid and bodybuilding. Muscle and Fitness Magazine, 1996. http://www.getbig.com/ articles/protein.htm

Friedwald WT, Levy RI and Fredrickson DS. Estimation of the concentration of low-density lipoprotein cholesterol in plasma, without use of the preparative ultracentrifuge. Clinical Chemistry, 18: 499-502. 1972.

Goodnight SH, Harris WS, Conner WE and Illingworth DR. Polyunsaturated fatty acids, hyperlipidemia, and thrombosis. Arteriosclerosis, 2: 87-113. 1982.

Griffin HD. Manipulation of egg-yolk cholesterol: a physiol- 
ogists view. World's Poultry Science Journal, 48: 101112. 1992.

Grundy SM. Monounsaturated fatty acids and cholesterol metabolism: implication for dietary recommendation. Journal of Nutrition, 119: 529-533. 1989.

Hammad SM, Siegel HS and Marks HL. Dietary cholesterol effects on plasma and yolk cholesterol fraction in selected lines of Japanese quail. Poultry Science, 75: 933942. 1996.

Harwood HJ, Chandler CE, Pellarin LD, Bangerter FW, Wilkins RW, Long CA, Cosgrove PG, Malinow MR, Marzetta CA, Pettini JL, Savoy YE and Mayne JT. Pharmacologic consequences of cholesterol absorption inhibition: alteration in cholesterol metabolism and reduction in plasma cholesterol concentration induced by the synthetic saponin b-tigogenin cellobioside (CP88818; tiqueside). Journal of Lipid Research, 34: 377395. 1993.

Haugh RR. The Haugh unit for measuring egg quality. United States Egg and Poultry Magazine, 43: 522-555. 1937.

Hillard LA, White HM and Pangburn SA. Characterization of apolipoprotein in chicken serum and egg yolk. Biochemistry, 11: 511-518. 1972.

Kobayashi $\mathbf{M}$ and Kurata S. The mass culture and cell utilization of photosynthetic bacteria. Process Biochemistry, 13: 27-29. 1978.

Leskanich CO and Noble RC. Manipulation of the n-3 polyunsaturated fatty acid composition of avian eggs and meat. World's Poultry Science Journal, 53: 155183. 1997.

Michella SM and Slaugh BT. Producing and marketing a specialty egg. Poultry Science, 79: 975-976. 2000.

Mutia R and Uchida S. Effects of feeding winged bean oil on cholesterol and lipid contents in egg and liver, and fatty acid composition of egg in Japanese quail. AsianAustralasian Journal of Animal Sciences, 12: 376-380. 1999.

Noble RC, Cocchi M and Turchetto E. Egg fat - a case for concern. World's Poultry Science Journal, 46: 109-118. 1990.

Phetteplace HW and Watkins BA. Lipid measurements in chickens fed different combinations of chicken fat and menhaden oil. Journal of Agricultural and Food Chemistry, 38: 1848-1853. 1990.

Salma U, Miah AG, Maki T, Nishimura $\mathbf{M}$ and Tsujii $\mathrm{H}$. Effect of dietary Rhodobacter capsulatus on cholesterol concentration and fatty acids composition in broiler meat. Poultry Science, 86: 1920-1926. 2007a.

Salma U, Miah AG, Tareq KMA, Maki T and H Tsujii. Effect of dietary Rhodobacter capsulatus on egg-yolk cholesterol and laying hen performance. Poultry Science, 86: 714-719. $2007 \mathrm{~b}$.

Tsujii H, Nishioka M, Salma U, Miah AG, Maki T and Lee MG. Comparative study on hypocholesterolemic effect of Rhodopseudomonas palustris and Rhodobacter capsulatus on rats fed a high-cholesterol diet. Animal Science Journal, 78: 535-540. 2007.

Vahouny GV, Chalcarz W, Satchithanandam S, Adamson I, Klurfeld D, and Kritchevsky D. Effect of soy protein and casein intake on intestinal absorption and lymphatic transport of cholesterol and oleic acid. American Journal of Clinical Nutrition, 40: 1156-1164. 1984.

Voss A, Reinhart M, Sankarappa S and Sprecher H. The metabolism of 7,10,13,16,19-docosahexaenoic acid in rat liver is independent of a 4-desaturase. Journal of Biological Chemistry, 266: 19995-20000. 1991.

Yeum KJ and Russell RM. Carotenoid bioavailability and bioconversion. Annual Review of Nutrition, 22: 483504. 2002. 